\title{
Follicular Thyroid Carcinoma Metastasizing to Base of Skull: A Rare Case Report
}

\author{
Niharika Bisht ${ }^{1}$, Abhishek Purkayastha ${ }^{1 *}$, Sankalp Singh ${ }^{1}$, Prabha Shankar Mishra ${ }^{2}$, Azhar \\ Husain $^{3}$ \\ ${ }^{1}$ Department of Radiation Oncology, Command Hospital (Southern Command), Pune, India \\ ${ }^{2}$ Department of Onco-Pathology, Command Hospital (Southern Command), Pune, India \\ ${ }^{3}$ Department of Nuclear Medicine, Command Hospital (Southern Command), Pune, India
}

*Corresponding Author: Abhishek Purkayastha, Department of Radiation Oncology, Command Hospital (Southern Command), Pune, India, Email: abhi5296@gmail.com

\begin{abstract}
Temporal bone metastasis in carcinoma thyroid is a rare occurrence. We present a case of welldifferentiated carcinoma thyroid that had an aggressive course of disease and despite undergoing primary surgery for carcinoma thyroid developed occipital and temporal bone metastasis. She was treated with palliative radiotherapy and is presently planned for a course of radioactive iodine ablation therapy.
\end{abstract}

Keywords: Follicular Thyroid Carcinoma; Base of skull; Metastasis; Radiotherapy.

Abbreviations: FTC: Follicular thyroid carcinoma, USG: ultrasonography, FNAC: fine needle aspiration cytology, CECT: contrast enhanced computed tomography, HPR: histopathology report, 18-FDG-PET: 18Fluoro-Deoxy-Glucose positron emission tomography, MRI: magnetic resonance imaging

\section{INTRODUCTION}

FTC is a common variant of thyroid cancer with common sites of metastasis being lymph nodes, lungs and bone. Though the follicular histology is the commonest variant of thyroid malignancy to develop calvarial metastasis, the base of skull remains a rare site of secondary deposits with very few case reports in literature [1, 2]. Here we describe the presentation and management of an indolent case of follicular variant of carcinoma thyroid who developed base of skull metastasis.

\section{CASe Report}

A 34-year-old lady presented to the surgical clinics with complaints of swelling in the neck region for the past 02 months. The growth of the swelling was insidious in onset and painless and progressive in nature. It was not associated with any skin changes and did not cause any difficulty in swallowing or breathing. On examination there was a $6 \mathrm{~cm} \times 5 \mathrm{~cm}$ swelling in the midline of the neck, which moved with swallowing. The patient was evaluated with a clinical diagnosis of a thyroid swelling and underwent an USG of the neck and FNAC. The USG neck revealed an enlarged right lobe of thyroid with multiple large mixed echogenic masses in the left lobe of thyroid. Her FNAC showed poorly differentiated carcinoma. A CECT scan of the neck showed an enlarged thyroid gland with a large hypodense mass measuring $6 \mathrm{~cm} \times 4 \mathrm{~cm} \times 4 \mathrm{~cm}$ epicentered in the left lobe, extending to the upper thorax with retro tracheal extension. The mass was abutting the carotid and the left internal jugular vein.

The patient underwent a total thyroidectomy with central compartment lymph node dissection and resection of a segment of the internal jugular vein. The final HPR was suggestive of a multicentric minimally invasive follicular carcinoma of the thyroid (Figure 1).

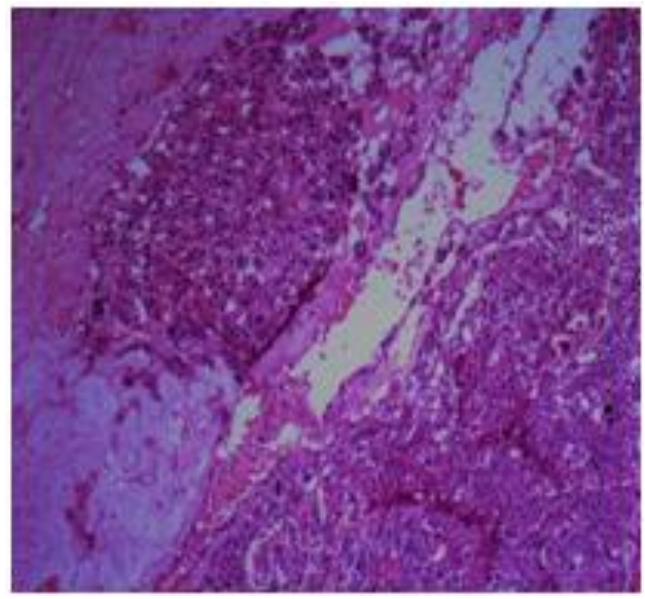

Figure1. Post total thyroidectomy specimen showing follicular carcinoma of the thyroid ( $H \& E 20 X)$. 
There was widespread capsular and vascular invasion and all the lymph nodes dissected were negative for tumor deposits. She was planned for radioactive iodine ablation but she had persistently raised Thyroid immunoglobin levels suggesting residual disease.

A CECT neck showed $2 \mathrm{~cm} \times 3 \mathrm{~cm}$ residual tumor at the posterolateral aspect of trachea and a similar lesion at posterolateral aspect of hypopharynx. A bronchoscopy was carried out and revealed a bulge in the posterior wall of the trachea. With the impression of residual disease, she underwent total laryngectomy with resection of the first three tracheal rings and a permanent tracheostomy. Postoperative histopathology was suggestive of poorly differentiated thyroid cancer with presence of vascular invasion. In the postoperative period the patient complained of recurrent episodes of headache and pain in the cervical spine region. She underwent MRI of the brain and spine which revealed an ill-defined expansile destructive lesion of the left occipital bone with soft issue component and also involving the left petrous temporal bone (Figure 2).

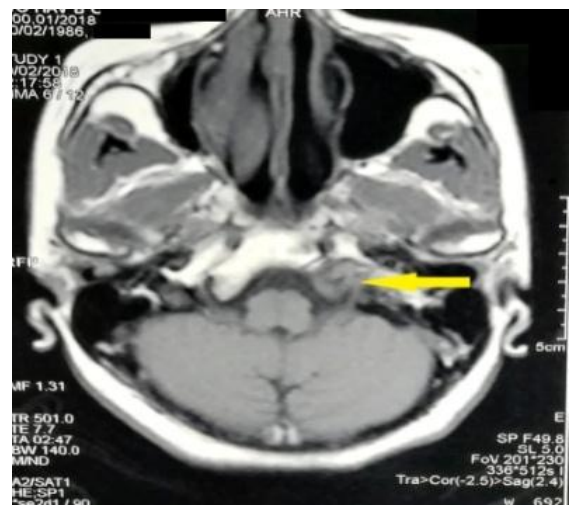

Figure2. Axial section of magnetic resonance imaging (MRI) of the brain and spine showing an ill-defined expansile destructive lesion of the left occipital bone with soft issue component and also involving the left petrous temporal bone (yellow arrow).

The soft tissue component also extended to the left neural foramina at cervical vertebrae level 2 and 3. An FDG-PET scan revealed metabolically active lytic lesion involving base of occipital bone and petrous part of temporal bone on the left side and also the cervical vertebrae CV2 and CV3 with a soft tissue component with a standard uptake value (SUVmax7.2) (Figure 3). An image guided biopsy from the skull base lesion revealed metastasis from follicular carcinoma of thyroid (Figure 4). The patient was counseled for surgery. However she was unwilling for the same. She was then treated with palliative radiotherapy to the occipital and temporal bones along with the cervical spine to a dose of 30 Gy in 10 fractions by conventional planning on a Theratron $780 \mathrm{E}$ telecobalt machine. She had significant pain relief and is presently pain free at 04 weeks post radiotherapy. She is now on Levothyroxine and oral calcium supplementation and is planned for radioiodine ablative therapy.

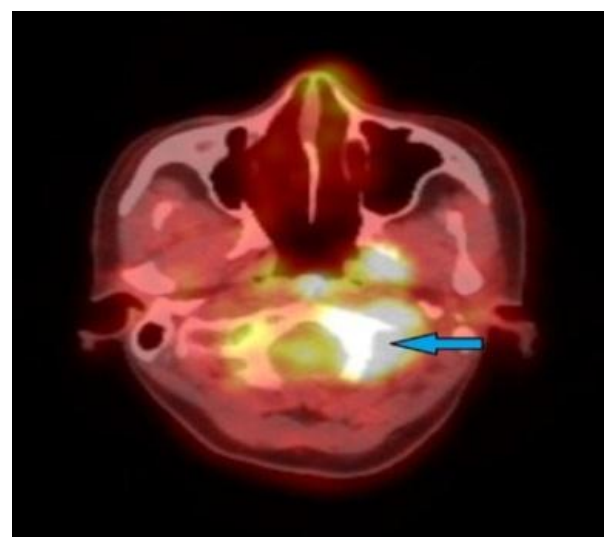

Figure3. 18-fluoro-deoxy-glucose positron emission tomography (18 FDG-PET) scan showing a metabolically active lytic lesion involving base of occipital bone and petrous part of temporal bone on the left side with significant SUV (blue arrow).

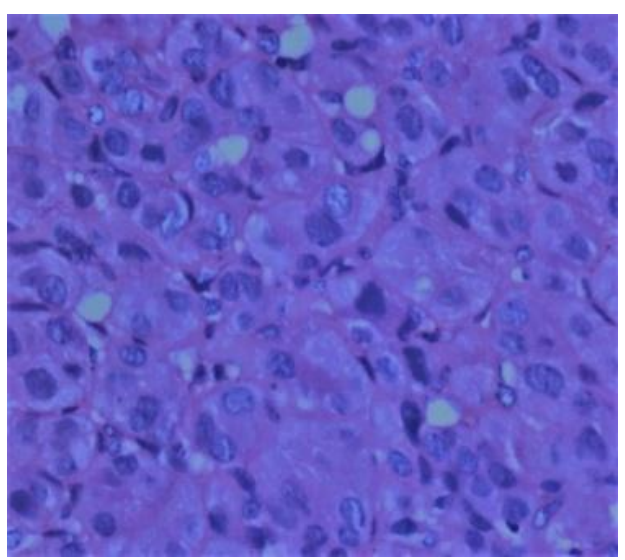

Figure4. Image guided biopsy from the skull base lesion showing metastasis from follicular carcinoma of thyroid $(H \& E 300 X)$.

\section{DISCUSSION}

The incidence of thyroid carcinoma increased almost $310 \%$ between 1950 and 2004, but mortality rates decreased by more than $44 \%$ [3]. There are three main known histologic types: differentiated (including papillary, follicular, and Hürthle), medullary, and anaplastic (aggressive undifferentiated tumor). Anaplastic thyroid carcinoma is almost uniformly lethal; however, most thyroid carcinoma deaths are 
from papillary, follicular, and Hürthle cell carcinomas, which account for nearly $95 \%$ of all thyroid carcinoma cases. Although thyroid carcinoma occurs more often in women, mortality rates are higher for men, probably because of older age at the time of diagnosis [4, 5]. Though the differentiated group of thyroid tumors does well prognostically, yet $5-25 \%$ of them develop distant metastasis in the long run $[6,7]$. The primary treatment modality remains surgery followed by treatment by radioiodine in selective cases. Bones remain a common site of metastasis with predominant involvement of long bones like femur and flat bones like the pelvis [7]. The other common sites of metastasis are the CNS and the lung. Treatment for metastatic disease depends primarily on the site. CNS metastasis needs to be addressed either by surgery or by external beam radiotherapy. For bony metastasis the options include radioiodine, external beam radiotherapy and bisphosphonates or denosumab.

Base of skull as a site of distant metastasis remains rare accounting for less than $3 \%$ of all secondaries, predominantly from follicular and less commonly the papillary variant [8-10]. The profile of patients with skull-based metastasis in FTC shows an age range from 23 to 74 years with a female preponderance [11]. Common signs and symptoms include local pain and cranial nerve involvement. The metastasis in the skull and calvaria is often associated with a lot of bony destruction and associated soft tissue component on imaging with a differential diagnosis of chordoma or chondrosarcoma [12, 13]. Surgical resection is an option for such patients but it can be associated with significant post op morbidity like bleeding and neurological deficit. Stereotactic radiotherapy is also an option for large unresectable skull based lesions [2]. In this case the patient declined surgery and was treated with external beam radiotherapy with a palliative intent to a dose of 30 Gy in 10 fractions which gave her significant pain relief. The prognosis in patients with skull metastasis with carcinoma thyroid as primary remains guarded. Li X et al, [14] reviewed the previous reports and calculated that overall survival among patients undergoing definitive treatment ranged from 14 months to 3.5 years from the discovery of the skull metastasis, while the survival of untreated patients was even shorter.

\section{CONCLUSiON}

Skull based metastasis remain a rare site of involvement in thyroid cancer. Its management is not well defined with treatment varying from case to case. Here we highlight a case of follicular cancer of thyroid gland treated initially with surgery and subsequently developed multiple skeletal metastases involving the cervical vertebrae and the skull base, which is an extremely rare site. She is on palliative therapy with radiotherapy and radioactive iodine ablation therapy.

\section{REFERENCES}

[1] Kotecha R., Angelov L., Barnett GH., Reddy CA., SuhJH., Murphy ES., et al. Calvarial and skull base metastases: expanding the clinical utility of Gamma Knife surgery. J Neurosurg.121 Suppl, 91-101 (2014).

[2] Mitsuya K., Nakasu Y., Horiguchi S., Harada H., Nishimura T., Yuen S, et al. Meta- static skull tumors: MRI features and a new conventional classification. J Neurooncol.104, 239-245 (2011)

[3] SEER Cancer Statistics Review, 1975-2006. Bethesda, MD: National Cancer Institute; 2009. Available at: Accessed October 20(2009).

[4] Altekruse S., Kosary C., Krapcho M., Neyman N., Aminou R., Waldron W., et al. SEER Cancer Statistics Review, 1975-2007. Bethesda, MD: National Cancer Institute (2010).

[5] Mazzaferri EL., Jhiang SM. Long-term impact of initial surgical and medical therapy on papillary and follicular thyroid cancer. Am J Med.97, 418-428 (1994).

[6] Cooper DS., Doherty GM., Haugen BR., Kloos RT., Lee SL., Mandel SJ., et al. Revised American Thyroid Association management guidelines for patients with thyroid nodules and differentiated thyroid cancer. Thyroid.19, 11671214 (2009).

[7] Khan SH., Hassan MU., Bhau RS. Iodine-131 avid distant metastasis in differentiated thyroid cancer: An initial institutional experience from the northern part of India. Indian J Nucl Med. 30, 227-232 (2015).

[8] Zettinig G., Fueger BJ., Passler C., Kaserer K., Pirich C., Dudczak R., et al. Long-term followup of patients with bone metastases from differentiated thyroid carcinoma - surgery or conventional therapy? ClinEndocrinol (Oxf).56, 377-382 (2002).

[9] Atkinson AL, Rosenthal A, Nardiello D. Follicular Thyroid Carcinoma Presenting as a Palpable Head Mass: A Case Report. Case Rep Oncol.3, 106-109 (2010). 
[10] Nagamine Y, Suzuki J, Katakura R, Yoshimoto T, Matoba N, Takaya K. Skull metastasis of thyroid carcinoma. Study of 12 cases.J Neurosurg. 63, 526-531 (1985).

[11] Matsuno A, Murakami M, Hoya K, Yamada SM, Miyamoto S, Yamada S, Son JH, Nishido H, Ide F, Nagashima H, Sugaya M, Hirohata T, Mizu- tani A, Okinaga H, Ishii Y, Tahara S, Teramoto A, Osamura RY, Yamazaki K, Ishida Y. Clinicopath- ological and molecular histochemical review of skull base metastasis from differentiated thyroid carcinoma. ActaHistochemCytochem.46, 129-136 (2013).
[12] Pallini R, Sabatino G, Doglietto F, Lauretti L, Fernandez E, Maira G. Clivus metastases: report of seven patients and literature review. ActaNeurochir (Wien). 151, 291-296 (2009).

[13] Rosahl SK., Erpenbeck V., Vorkapic P., Samii M. Solitary follicular thyroid carcinoma of the skull base and its differentiation from ectopic ade- noma--review, use of galectin-3 and report of a new case. ClinNeurolNeurosurg. 102, 149155 (2000).

[14] Li X., Zhao G., Zhang Y., Ding K., Cao H., Yang D., et al. Skull metastasis revealing a papillary thyroid carcinoma. Chin J Cancer Res. 25, 603-607 (2013).

Citation: Niharika Bisht, Abhishek Purkayastha, Sankalp Singh, Prabha Shankar Mishra, Azhar Husain. Follicular Thyroid Carcinoma Metastasizing to Base of Skull: A Rare Case Report. ARC Journal of Cancer Science 2018; 4(1):14-17. DOI: http://dx.doi.org/10.20431/2455-6009.0401004

Copyright: (c) 2018 Authors. This is an open-access article distributed under the terms of the Creative Commons Attribution License, which permits unrestricted use, distribution, and reproduction in any medium, provided the original author and source are credited. 